THE GRADUATE INSTITUTE I GENEVA

CENTRE FOR INTERNATIONAL

ENVIRONMENTAL STUDIES

(1) Research Paper 16 | 2013

\title{
RE-ORIENTING THE SUSTAINABLE DEVELOPMENT SNAKE
}

\author{
J. E Viñuales
}

(1) Research Paper 16 | 2013 


\title{
Re-orienting the Sustainable Development Snake
}

\author{
J. E. Viñuales*
}

\author{
Abstract \\ Introduction \\ 1. The sustainable development snake \\ 2. Re-orienting the snake \\ 2.1. Identifying priorities: an alternative model \\ 2.1.1. Participation \\ 2.1.2. Differentiation \\ 2.1.3. Decarbonisation \\ 2.1.4. Innovation and dissemination
}

2.2. Relations with the concept of sustainable development

3. An initial exploration

\begin{abstract}
Efforts toward sustainable development are failing. The reason is that the concept of sustainable development no longer provides an adequate umbrella for the main challenge currently faced by global environmental governance, namely implementation. The very strengths of the concept of sustainable development are turning into fatal weaknesses. Vague enough to bring all States and other stakeholders to the table of negotiations, the concept of sustainable development was very successful in managing the political collision between 'development' and 'environment' throughout the 1980s and the 1990s. It was a formidable tool to find balance as well as for normative development. But it is inadequate to move forward to the next phase, i.e. implementation. This article introduces an alternative model, based on four strategic priorities (participation, differentiation, decarbonisation, innovation and technology dissemination). It maps different levels at which these priorities could be pursued in order to make global environmental governance more effective. The article is not against the concept of 'sustainable development' as a worthy fight, but as a weapon.
\end{abstract}

I am grateful to Liliana Andonova, Dan Farber, Jacques Grinevald, Martina Kunz, Elisa Morgera, Joost Pauwelyn and Harro van Asselt for valuable comments on an earlier version of this article. 


\section{Introduction}

When attempting to tackle a broad question, one faces two main perils. First, if poorly designed, a broad question may be a dead end. Social science terminology is more suitable to clarify this risk. A question that seeks to clarify and understand the dynamics of an ill-defined 'dependent variable' stands limited chances of success, irrespective of the efforts invested in answering the question. Indeed, sooner or later, one will be constrained to redefine the initial question (the initial dependent variable) to be able to provide a meaningful answer. The second peril lies in the types of answers that broad questions may require. Broad questions sometimes call for broad answers. Such answers may advance our understanding of a phenomenon but may not be easily used for guiding policy efforts. Thus, the type of answers one seeks is an important consideration in shaping the type of question one asks.

These basic observations provide the background for the broad question addressed in this issue of RECIEL. I asked several distinguished contributors a broad question, of the inadequacies of which I remain fully responsible. The question is as follows: what fundamental aspects of global environmental governance must be changed in order to make progress in the implementation of international environmental law? This is certainly a broad and risky question. Yet, I decided to pursue it nevertheless on the basis of two considerations.

First, in the run-up and immediate aftermath of the Rio+20 Summit, the question appeared fitting. Paragraph 20(a) of the UN General Assembly resolution convening the Rio Summit had set as its main objective the assessment of 'the progress to date and the remaining gaps in the implementation of the outcomes of the major summits on sustainable development'. The focus was clearly on implementation and the international community seemed open, at least intellectually, to fresh ideas.

'Implementation of Agenda 21, the Programme for the Further Implementation of Agenda 21 and the outcomes of the World Summit on Sustainable Development', U.N. Doc. A/RES/64/236 
Second, I endeavoured to clarify the target of this question by identifying four 'Gordian knots' that, in my view, would need to be cut before meaningful progress can be made in the implementation of international environmental law, namely: (a) participation; (b) differentiation; (c) decarbonisation; and (d) innovation and the dissemination of technologies. Articles were elicited for each of these more specific targets, although some of the articles provide answers that cut across the four issues.

In this framing article, my purpose is to clarify the question, by spelling out its underpinnings, as well as to introduce a conceptual model that would help perform the tasks that the concept of sustainable development seems increasingly unsuitable to perform. RECIEL offers perhaps the most appropriate setting for placing this debate on the agenda of academics and policy makers. Born at the time of the Rio Conference of 1992, RECIEL has advanced the agenda of sustainable development for more than two decades, and it reaches not only lawyers but also social scientists and policy circles. Thus, this article seeks both to open a debate and to outline a research programme that I intend to pursue in the years to come.

\section{The Sustainable Development Snake}

Where should we start if our goal is to improve the implementation of international environmental law? Underlying this broad question, there is an understanding of the evolution of global environmental governance in the last fifty years. By global environmental governance, I refer here to 'the entirety of regulations put forward with reference to solving specific denationalized and deregionalized problems or providing transnational common goods [relating to the protection of the environment].' 2 This definition targets primarily environmental regimes based on treaties (whether simple or complex), global environmental conferences, and a variety of transnational frameworks such as public-private partnerships or forums with mixed composition (e.g. the International Forum on Chemical Safety). A specific understanding of the evolution of this broad process towards the denationalized government (governance) of environmental problems lies at the roots of the question addressed by this issue of RECIEL. It is therefore necessary to spell out this understanding as clearly as possible.

Efforts toward sustainable development are failing. The reason is that the concept of sustainable development no longer provides an adequate umbrella for the main challenge currently faced by global environmental governance,

M. Zürn, 'Global Governance as Multi-Level Governance’, in D. Levi-Faur, The Oxford Handbook of Governance (Oxford University Press, 2012), p. 730 ; J. G. Speth, P. Haas, Global Environmental Governance (Washington D.C.: Island Press, 2006), chapter 2 (detailing the main environmental problems requiring global action). 
namely implementation. The very strengths of the concept of sustainable development are turning into fatal weaknesses. Vague enough to bring all States and other stakeholders to the table of negotiations, the concept of sustainable development was very successful in managing the political collision between 'development' and 'environment' throughout the 1980s and the 1990s. It was a formidable tool to find balance as well as for normative development. But it is inadequate to move forward to the next phase, i.e. implementation. Let elaborate in some more detail on this basic understanding.

Born in the 1980s as a conservation concept, ${ }^{3}$ 'sustainable development' was brought to light by the report of the Brundtland Commission, 'Our common future', in 1987, ${ }^{4}$ and crowned at the Earth Summit, in 1992, ${ }^{5}$ as the leading concept guiding global efforts to protect the environment. Other concepts had been developed over time, including the concept of 'eco-development' or that of a 'green economy', ${ }^{6}$ but they were unsuccessful in gathering consensus among different stake-holders. Sustainable development proved to be superior in accommodating the developmental concerns expressed by countries such as Brazil, India or Algeria since the late 1960s. Yet, it did not crack the environment-development equation. Rather, it drew a veil over it to make consensus possible.

3 IUCN, UNEP, WWF, World Conservation Strategy. Living Resource Conservation for Sustainable Development, 1980.

4 Report of the World Commission on Environment and Development: Our Common Future, U.N. Doc A/42/427, Annex, 4 August 1987 ('Our Common Future'), Part I, chapter 2, section I ('The Concept of Sustainable Development').

5 See Rio Declaration on Environment and Development, 13 June 1992, U.N. Doc. A/CONF.151/26 ('Rio Declaration'), particularly principles 4 and 8. For a short conceptual history of sustainable development see A. E. Egelton, Sustainable Development: A History (Dordrecht/Heidelberg/New York/London : Springer, 2012). At least three book-length legal studies have been devoted to the evolution of sustainable development : N. Schrijver, 'The Evolution of Sustainable Development in International Law: Inception, Meaning, and Status', in Recueil des cours de l'Académie de droit international, vol. 329 (2007), pp. 217-412 ; C. Voigt, Sustainable Development as a Principle of International Law (Leiden : Martinus Nijhoff, 2009) (with a focus on climate change and trade law); V. Barral, Le développement durable en droit international: Essai sur les incidences juridiques d'un concept évolutif' (Ph.D. dissertation defended at the European University Institute, 2007).

6 The concept of 'eco-development' was advanced in as part of the preparation of the so-called 'Founex II' conference, held in 1974. The project paper by Ignacy Sachs can be found in the collection of papers of Maurice Strong (IV. UN Conference on the Human Environment/UN Environment Programme years: 1970-1975, Series III. UNEP file: 1968 Jan-1975 Dec, Subseries B), donated by Strong himself to the Environmental Science and Public Policy Archives, Harvard University. Further elaboration of this concept can be found in B. Glaeser (ed.), Ecodevelopment : concepts, projects, strategies (Oxford/New York: Pergamon Press, 1984), which includes a preface by Ignacy Sachs. The concept of 'green economy' is of more recent vintage. Its origins are usually traced back to a book by D. W. Pearce, A. Markandya, E. Barbier, Blueprint for a Green Economy (London : Earthscan, 1989). The 'blueprints' offered by the authors are however embedded within the concept of sustainable development and as an interpretation of it. This same approach underlied the GA Resolution convening the Rio+20 Summit. A modernized version of the green economy concept appears in E. Barbier, A Global Green New Deal: Rethinking the Economic Recovery (Cambridge University Press, 2010) as well as in UNEP, The Green Economy Report - A Synthesis for Policy Makers (Nairobi: UNEP, 2011). On this concept, see the article by E. Morgera and A. Savaresi in this issue of RECIEL. 
Throughout its life, the concept never stopped being what it had been since the beginning, namely a 'diplomatic trick' to bring all stakeholders under a common banner. In order to be effective, it had perforce to have very limited content. Who would disagree with meeting the needs of the present without compromising those of future generations? Even the more elaborated version of the concept, as consisting of three pillars (environmental protection, economic development, and social development), ${ }^{7}$ tells us little about what should be our strategic priorities in tackling environmental degradation or poverty. Is the development of genetically modified organisms for agriculture consistent with sustainable development? Some would say no, as we run the risk of introducing poorly understood forms of life into the environment, whereas others would say that GMOs are key to addressing food security and developing water-efficient seeds. Is the building of nuclear energy facilities consistent with sustainable development? Some would say no, as the techniques for storing spent nuclear fuel are still controversial and there is always a risk of nuclear accidents, whereas others would point out that nuclear energy is the most realistic way to provide cheap electricity in emerging countries without multiplying the emissions of greenhouse gases. Is the development and enforcement of intellectual property rights consistent with sustainable development? Some would say no, as IPRs limit the diffusion of environmental technologies, whereas others would say that without IPRs there would be no innovation or diffusion. There is no need to multiply the examples. Suffice it to note that these as well as other more specific questions are the types of issues that must be solved in order to move forward on the implementation front. Despite efforts towards harnessing different disciplines to produce a science of sustainability ${ }^{8}$ or, at least, a specific branch of economics ('sustainability economics') ${ }^{9}$ that would be capable of providing the tools to decide trade-offs, we are far from having reached this point. ${ }^{10}$ Sustainability, which is a by-product of the concept of sustainable development, seems inadequate to organize the efforts towards the resolution of these questions. Even in legal disciplines, which, by definition, are supposed to define conducts and decide trade-offs, these efforts have been

7 See GA Resolution S/19-2, 28 June 1997, Annex, 'Programme for the Further Implementation of Agenda 21', Statement of Commitment, para. 3 'We are convinced that the achievement of sustainable development requires the integration of its economic, environmental and social components'.

8 See W. Clark, N. Dickson, 'Sustainability Science: The Emerging Resarch Program' (2003) 100 Proceedings of the National Academy of Sciences of the United States of America 8059 ; W. Clark, 'Sustainability science: a room of its own' (2007) 104 Proceedings of the National Academy of Sciences of the United States of America 1737.

9 See S. Baumgartner, M. Quaas, 'What is sustainability economics?' (2010) 69 Ecological Economics 445.

10 See A. Gasparatos, A. Scolobig, 'Choosing the most appropriate sustainability assessment tool' (2012) 80 Ecological Economics 1. 
unsuccessful. $^{11}$ By creating an all-encompassing concept, necessary to accommodate the situation of all stakeholders, we took the risk of foregoing the ability of setting clear priorities.

This risk was worth-taking at the time. The special session of UNEP's Governing Council held in 1982 (often referred to as Stockholm+10) had yielded a grim picture. Despite efforts deployed since the late 1960s to place the environment in the agenda of policy-makers, all major environmental indicators had continued to deteriorate. At the roots of this failure was the inability of the environmental message to spread beyond environment ministries, particularly to those circles of government that handled economic and social policies. As noted by Gro Harlem Brundtland in an interview given in 2004, a key reason why previous efforts had been ineffective was the failure to garner support from government economists. ${ }^{12}$ When the World Commission on Environment and Development (WCED) was established, in 1983, a key dimension was therefore to reach out to this skeptical or simply unfamiliar audience. The message was therefore adjusted. 'Sustainable development' would indeed align economic and environmental considerations. The elaboration of the concept of sustainable development by the WCED amounted to nothing short of a breakthrough. The concept breathed new life into global environmental governance and triggered a decade of considerable normative developments. One important indication of this renewed activity is provided not only by the conclusion of several important environmental treaties after the Earth Summit of 1992 (including the UNFCCC ${ }^{13}$ and its Kyoto Protocol, ${ }^{14}$ the CBD ${ }^{15}$ and its Biosafety Protocol, ${ }^{16}$ the UN Convention to Combat Desertification, ${ }^{17}$ the Straddling Fish Stocks Agreement, ${ }^{18}$ the Rotterdam Convention $^{19}$ and the Stockholm Convention ${ }^{20}$ ) but also by the increase in the number of ratifications of major existing conventions. ${ }^{21}$

11 See V. Lowe, 'Sustainable Development and Unsustainable Arguments', in A. Boyle, D. Freestone (eds.), International Law and Sustainable Development : Past Achievements and Future Challenges (Oxford University Press, 1999), pp. 19-37.

12 Interview Gro Harlem Brundtland, March 2004, referred to in H. Selin, B.-O. Linner, 'The Quest for Global Sustainability: International Efforts on Linking Environment and Development', CID Graduate Student and Postdoctoral Fellow Working Paper No. 5, January 2005, p. 47.

13 United Nations Framework Convention on Climate Change, 9 May 1992, 31 I.L.M. 849.

14 Kyoto Protocol to the United Nations Framework Convention on Climate Change, Kyoto, 11 December 1997, 2303 U.N.T.S. 148.

15 Convention on Biological Diversity, 5 June 1992, 1760 U.N.T.S. 79.

16 Cartagena Protocol on Biosafety to the Convention on Biological Diversity, 29 January 2000, 39 I.L.M. 1027 (2000).

17 United Nations Convention to Combat Desertification in those Countries Experiencing Serious Drought and/or Desertification, Particularly in Africa, 17 June 1994, U.N. Doc. A/AC.241/15/Rev. 7 (1994), 33 I.L.M. 1328.

18 Agreement for the Implementation of the Provisions of the United Nations Conventions on the Law of the Sea of 10 December 1982 Relating to the Conservation and Management of Straddling Fish Stocks and Highly Migratory Fish Stocks, 4 August 1995, 2167 U.N.T.S. 88.

19 Rotterdam Convention on the Prior Informed Consent Procedure for Certain Hazardous Chemicals and Pesticides in International Trade, 10 September 1998, 2244 U.N.T.S. 337. 
But this is not to say that actual implementation followed. Despite its normative pull, the concept of sustainable development could still not provide an answer to the very real conflicts opposing the two terms of the environmentdevelopment equation. Whereas, from a conceptual standpoint, sustainable development amounted to an aspiration, almost a 'belief' in the synergies between development and environmental protection, in practice, such synergies proved to be far from obvious. The risk of clashes started to materialize in the late 1990s, as the attention focused on implementation. A first indication was provided at the so-called Earth Summit+5 meeting of the UN General Assembly, in 1997. As noted in the 'Programme for the Further Implementation of Agenda 21', adopted by the GA, 'Five years after the United Nations Conference on Environment and Development, the state of the global environment has continued to deteriorate [ ... ] Some progress has been made in terms of institutional development, international consensus-building, public participation and private sector actions and, as a result, a number of countries have succeeded in curbing pollution and slowing the rate of resource degradation. Overall, however, trends are worsening'. ${ }^{22}$ But the shift from normative development to a specific focus on implementation became clearer in the run-up to the World Summit on Sustainable Development, held in Johannesburg (South Africa) in August/September 2002, ${ }^{23}$ and it was subsequently confirmed by other global conferences, most recently the 'Rio+20' Summit, held in Rio de Janeiro (Brazil) in June 2012. ${ }^{24}$

As implementation becomes more and more urgent, the very strength of the concept of sustainable development (its ability to encompass very different issues without clarifying the relations among them) is turning into its main weakness. As suggested by the still fresh impression left by the Rio+20 Summit, when close to 200 States come to the table of negotiation with such a different array of topics and concerns (all encompassed, of course, by the concept of sustainable development) as trade and the green economy, population dynamics, disaster reduction and resilience, oceans or sustainable cities, to name just a few

20 Stockholm Convention on Persistent Organic Pollutants, 22 May 2001, 40 I.L.M. 532 (2001).

21 See UNEP, Global Environmental Outlook 5. Environment for the future we want (UNEP, 2012), chapter 17, p. 464, figure 17.1.

22 GA Resolution S/19-2, 28 June 1997, Annex, 'Programme for the Further Implementation of Agenda 21', para. 9.

23 Report of the World Summit on Sustainable Development, Johannesburg, South Africa, 26 August-4 September 2002, U.N. Doc. A/CONF.199/20, in particular Resolution 2, 'Plan of Implementation of the World Summit on Sustainable Development'. The focus on implementation and, more specifically, on multi-stakeholder partnerships, was largely an attempt to compensate for the lack of political will to take bolder steps. See L. Andonova, M. Levy, 'Franchising Governance: Making Sense of the Johannesburg Type II Parternships', in O. Schram Stokke, Ø. B. Thommessen (eds.), Yearbook of International Co-operation on Environment and Development (London: Earthscan Publications, 2004), pp. 19-31.

24 GA Resolution A/RES/66/288, 11 September 2012, Annex, 'The future we want'. 
issues where the Summit secretariat prepared an 'issue brief', ${ }^{25}$ it is very difficult indeed to set priorities. Now, how can we advance implementation without lifting the veil drawn by sustainable development over the real tradeoffs between economic and environmental considerations? There is, of course, significant room for synergies, ${ }^{26}$ but it would be unrealistic to ignore the important trade-offs that must be tackled.

Ignoring the trade-offs, for the sake of the belief in synergies, presents an additional problem. The pull of the development pillar is amplified by the clear economic priorities that, following the 2008 crisis, are increasingly being expressed by industrialised countries. As the center of gravity shifts from environment to development and growth, there is a risk that what is presented as a 'synergy' may be more appropriately characterised as an attempt to find or highlight the environmental dimension of measures and policies adopted for predominantly development/growth reasons. ${ }^{27}$ To use an image, environmental protection would be seen as an 'immigrant' in the land of development/growth. As such, it would only have the scope of action that is consistent with development/growth. If environmental protection were to collide with development/growth considerations, the latter would likely prevail. This is not necessarily a problem in all situations. But it is indeed a problem if the stance taken in favour of development/growth is not presented openly or is camouflaged with secondary environmental objectives.

25 Issue briefs were also prepared for topics such as options for developing and strengthening an international forum on sustainable development, ideas on sustainable development goals and indicators, green jobs and social inclusion, food security and sustainable agriculture, regional/national/local level governance for sustainable development, water, science and technology for sustainable development, sustainable low carbon transport in emerging and developing economies, migration and sustainable development, or finance for the transition to a green economy. The 'Issues Briefs' are available at : www.uncsd2012.org (visited on 27 november 2012).

26 For a study of synergies see: P.-M. Dupuy, J. E. Viñuales (eds.), Harnessing Foreign Investment to Promote Environmental Protection: Incentives and Safeguards (Cambridge University Press, 2013).

27 The emphasis on development and growth, especially during the 1990s, is documented in S. F. Bernstein, The Compromise of Liberal Environmentalism (New York: Columbia University Press, 2001). It is interesting to compare, in this regard, the outcome document of the Rio + 20 Summit of 2012, above n. 24, with the resolution adopted by the UN General Assembly in December 1971, 'Development and Environment' (Res. 2849 (XXVI)), which was at the time seen as threat looming over the success of the Stockholm Conference on the Human Environment (1972). Paragraph 11 of Res. 2849 (XXVI) 'reiterate(d) the primacy of independent economic and social development as the main and paramount objective of international co-operation, in the interests of the welfare of mankind and of peace and world security' (italics added). Paragraph 2 of 'The future we want' also stressed, in contemporary language, the primacy of the economic and social development pillars of sustainable development: 'Poverty eradication is the greatest global challenge facing the world today and an indispensable requirement for sustainable development. In this regard, we are committed to freeing humanity from poverty and hunger as a matter of urgency.' (italics added). 
The understanding presented so far can be summarised graphically:

Figure 1: The 'Sustainable Development Snake'

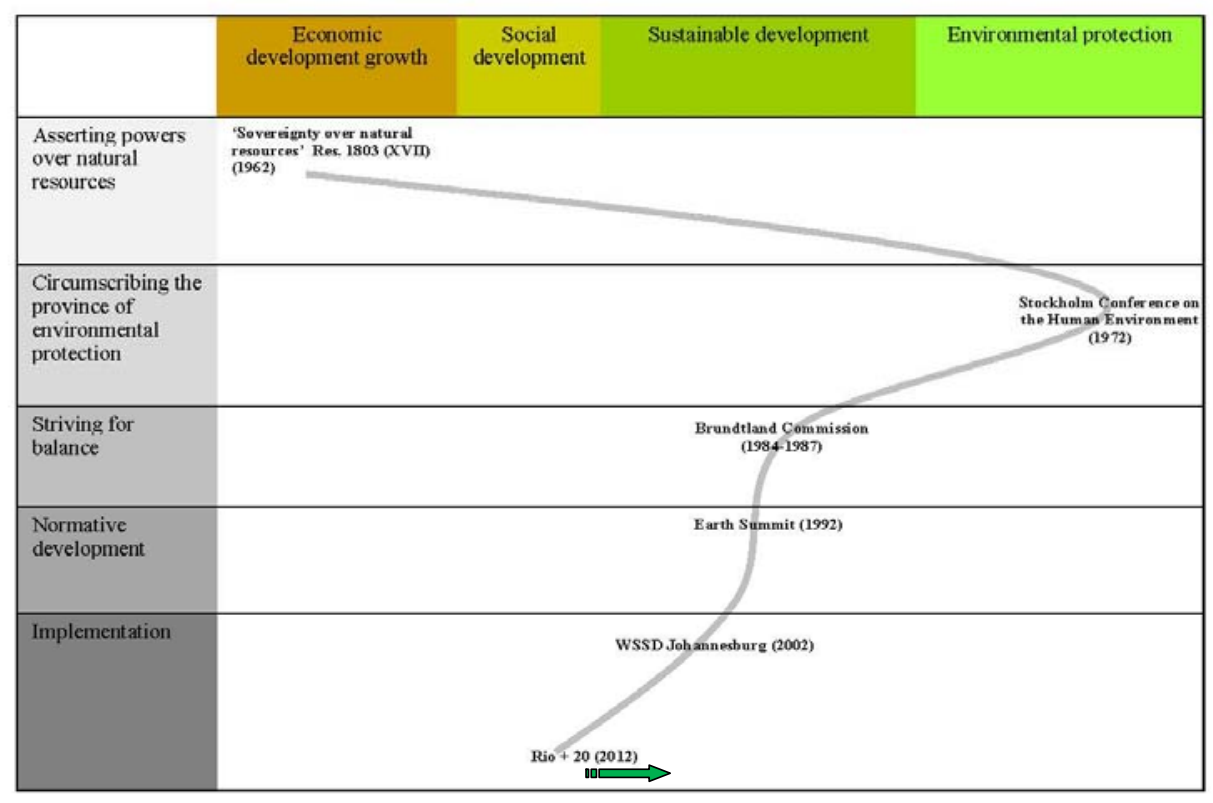

Sustainable development is turning brownish. It is no longer capable of guiding global environmental governance because it is ill-suited (i) to take clear stances where there are trade-offs between environmental, social and economic considerations, and (ii) to set strategic priorities for action. We need a new model, whether explicit or implicit, which is more suitable for the implementation stage of global environmental governance, a model that confronts (instead of obscuring) the sometimes hard choices that must be made to tackle the often competing demands of development and environmental protection and that derives clear strategic priorities from such choices.

\section{Re-orienting the Snake}

The two problems identified in the preceding section beg two additional questions: if the concept of sustainable development is inadequate to setting clear priorities, what should these priorities be? And, to the extent that they can be identified, what would be the relationship between making progress with respect to these priorities and the negotiation umbrella offered by the concept of sustainable development? 


\subsection{Identifying Priorities: An Alternative Model}

Regarding the first question, my own view is that we need to focus on the four Gordian knots identified in the introduction, namely (a) participation, (b) differentiation, (b) decarbonisation, and (d) innovation and technology dissemination. These four knots could be viewed, to use an image, as 'acupunctural points' in the body of global environmental governance that must be tackled as a matter of priority in order to re-orient the sustainable development snake. The angle targeted by these re-orientation efforts (represented in figure 1 by a green arrow) would depend on the calibration of the four knots.

By way of illustration, little openness to individuals or civil society ${ }^{28}$ (potentially amplified by a civil society tissue unaccustomed to participation), unrealistic differentiation among States (e.g. ignoring the situation of emerging economies), a focus on fossil energies (suggested by the huge resources invested in the last decade in the extraction of fossil energy resources), and little technology transfer (with a clear predominance of the IPRs approach) are all features that characterise the limited effectiveness of global environmental governance at present. Progress on one or more of them would yield different models of global environmental governance or, in other words, it would change the 'infrastructure' of global environmental governance. Figure 2 presents this model graphically:

28 In the terminology developed in the seminal paper by Sh. Arnstein this deficient degree of participation could be referred to as 'non-participation' or, at best 'tokenism' (information, consultation, placation). See Sh. Arnstein, '’A Ladder of Citizen Participation' (1969) 35 Journal of the American Institute of Planners 216. 
Figure 2: An Alternative Model

\begin{tabular}{|c|c|c|c|c|c|}
\hline \multicolumn{3}{|c|}{ Participation } & \multicolumn{3}{|c|}{ Differentiation } \\
\hline \multicolumn{3}{|c|}{ Re-orientation } & \multicolumn{3}{|c|}{ Re-orientation } \\
\hline $\begin{array}{l}\text { Limited and } \\
\text { ineffective } \\
\text { participation }\end{array}$ & $\begin{array}{l}\text { Middle grounds } \\
\text { (e.g. use of } \\
\text { regional human } \\
\text { rights frameworks } \\
\text { through the } \\
\text { broadening of } \\
\text { their participation } \\
\text { provisions to } \\
\text { include } \\
\text { environmental } \\
\text { considerations) }\end{array}$ & $\begin{array}{l}\text { Targeted efforts to } \\
\text { strengthen the three } \\
\text { pillars of } \\
\text { environmental } \\
\text { participation } \\
\text { domestically and } \\
\text { globally }\end{array}$ & $\begin{array}{c}\text { Obsolete } \\
\text { differentiation }\end{array}$ & $\begin{array}{l}\text { Middle grounds } \\
\text { (e.g. incorporation } \\
\text { of emerging } \\
\text { economies) }\end{array}$ & $\begin{array}{c}\text { Evolving } \\
\text { differentiation }\end{array}$ \\
\hline \multicolumn{3}{|c|}{ Decarbonisation } & \multicolumn{3}{|c|}{ Innovation and technology dissemination } \\
\hline \multicolumn{3}{|c|}{ Re-orientation } & \multicolumn{3}{|c|}{ Re-orientation } \\
\hline $\begin{array}{c}\text { Strong } \\
\text { commitment } \\
\text { to the } \\
\text { prevalence of } \\
\text { fossil energy } \\
\text { sources (e.g. } \\
\text { through sunk } \\
\text { costs) }\end{array}$ & $\begin{array}{l}\text { Energy mix (e.g. } \\
\text { use of lower } \\
\text { emissions fossils - } \\
\text { gas - , larger share } \\
\text { of renewables, } \\
\text { smart grids, geo- } \\
\text { engineering) }\end{array}$ & $\begin{array}{l}\text { Large-scale use of } \\
\text { renewable energies }\end{array}$ & $\begin{array}{l}\text { Only through trade } \\
\text { and IPRs }\end{array}$ & $\begin{array}{l}\text { Middle grounds } \\
\text { (e.g. public } \\
\text { research, IPR } \\
\text { markets, } \\
\text { compulsory } \\
\text { licensing) }\end{array}$ & $\begin{array}{c}\text { Preferential } \\
\text { availability of } \\
\text { hard and soft } \\
\text { technologies }\end{array}$ \\
\hline
\end{tabular}

Each knot is a front-line where competing considerations affront each other. Different stances could be taken according to different issue-areas. The three columns under each knot are only intended to reflect the current situation (left column), the most progressive scenario now being considered (right column), and a variety of combinations or middle grounds (middle column). In fact, these three columns must be seen as a continuum within which several more specific front-lines could be open. Let me now discuss each knot in some more detail.

\subsubsection{Participation}

Out of the four knots, 'participation' is the most fundamental one. It aims at creating the social forces (individuals and groups, seen as citizens, activists, but also consumers, entrepreneurs and producers) capable of exerting pressure on, or of supporting, governments and economic operators for them to change their course of action. ${ }^{29}$ Such an empowerment tactic or, viewed from a different standpoint, this attempt at 'outsourcing pressure' would be very important in

29 For an analytical framework conceptualising global environmental governance at different interconnected levels see L. Andonova, R. Mitchell, 'The Rescaling of Global Environmental Politics' (2010) 35 Annual Review of Environment and Resources 255. 
laying the foundation for a re-orientation of investment at the level of governments and industry towards greener products and processes.

One avenue to achieve this reorientation would be education and awareness. But aside from the slow pace at which this approach evolves, it is still necessary to mainstream environmental demands into the political process and the markets (through consumer demand but also through competitive pressure from industries with greener products). Environmental participation, understood as access to environmental information, participation in environmental decisionmaking and access to courts to enforce the two latter rights, ${ }^{30}$ is critical in this regard.

It has been shown that environmental groups have indeed won battles against business lobby groups more often that it is usually assumed. ${ }^{31}$ The next frontier would be to take a more nuanced look not only at the battle between environmental groups and business groups, but also at how to move towards a critical mass of businesses who would benefit, because of the type of products or services they provide, from the passing of environmental legislation. ${ }^{32}$ Whereas current models predict a significant level of pull (impact on governments) from both environmental groups and business lobbies, ${ }^{33}$ if part of the latter group were to join the former (i.e. if green businesses were seeking to shape the market conditions - through regulatory change - in a way that would give them a comparative advantage) environmental action would become more likely. In turn, if some States became, for this reason, more prone to environmental action on certain areas, the critical mass reached domestically could, if extended to a critical mass of States, ${ }^{34}$ tilt the balance of at least some international environmental negotiations. ${ }^{35}$ The question, of course, is how to reach that critical mass (domestically and then internationally).

30 The most sophisticated instrument so far in this regard is the Convention on Access to Information, Public Participation in Decision-making and Access to Justice in Environmental Matters, 25 June 1998, 2161 U.N.T.S. 447, adopted within the framework of the United Nations Economic Commission for Europe but also open to the accession of other States. The Aarhus Convention implements the contents of principle 10 of the Rio Declaration, above n. 5.

31 See e.g. M. Kraft, S. Kamieniecki (eds.), Business and Environmental Policy: Corporate Interests in the American Political System (Cambridge MA : MIT Press, 2007).

32 Complementarity between these two groups could be fostered through PPPs but only if the latter are used to change the business model of some industries instead of simply channelling funds towards environmental friendly goals or projects. In a way, PPPs would become confidence building measures.

33 S. Dietz, C. Marchiori, A. Tavoni, 'Domestic politics and the formation of international environmental agreements', Centre for Climate Change Economics and Policy Working Paper 100 and Grantham Research Institute on Climate Change and the Environment Working Paper 87, 2012.

34 On the links between 'subglobal' action and 'global' action see D. Farber, 'Carbon Leakage versus Policy Diffusion : The Perils and Promise of Subglobal Climate Action' (2013) 13 Chicago Journal of International Law, forthcoming (arguing that subglobal climate action in some countries, may in fact, facilitate action in other countries and thus build confidence for global action).

35 From a normative standpoint, it has been argued that the current stagnation experienced in some international legal fora (States' negotiations within the framework offered by international organizations) is being compensated by a major rise in 'informal international law making', namely normative generation involving non-traditional actors (agencies, cities, central banks and non-state 
I believe that participation would be particularly important not only for strengthening environmental lobby groups but also to inform consumers, change their consumption patterns, and steer business investment into products (substitutes to 'brown' products, or new green products/services) that match the new patterns. The combined impact of stronger environmental groups and proenvironment business lobbies could reach a critical mass and, depending on the number of States undergoing this process, a critical mass could also be reached in international negotiations. Participation would be key for what could be referred to as a 'green dominos' theory.

Participation would also be very important to keep attempts to protect the environment within a course that is consistent with the respect of fundamental human rights. 'Environmentalism', if not properly handled, could involve severe restrictions of fundamental freedoms for the sake of protecting the environment. The process leading to potential restrictions must be kept under close scrutiny not only by political institutions but also by those most directly concerned, individuals, as the holders of rights. ${ }^{36}$ The forces unleashed through participatory processes would, in turn, influence progress on the frontlines open under the three other knots.

\subsubsection{Differentiation}

On the question of differentiation, it is increasingly understood in academic and policy circles that it is not just a matter of fairness but one of effectiveness of international environmental law. Different techniques have been developed to introduce some levels of differentiation of international obligations. ${ }^{37}$ They consist essentially of a combination of adjusted obligations and assistance (financial and technical). It would be unhelpful to organize these techniques along a spectrum going from no-differentiation to excessive differentiation as what really matters is not the 'degree' of differentiation but 'how' differentiation is achieved.

actors), processes (networks and schemes, rather than international organizations) and outputs (standards, guidelines, NAMAs and indicators, rather than treaties). See J. Pauwelyn, R. Wessel, J. Wouters (eds.), Informal International Lawmaking (Oxford University Press, 2012). For a selection of case-studies, see A. Berman, S. Duquet, R. Wessel, J. Wouters (eds.), Informal International Lawmaking: Case Studies (Oslo: TOAEP Academic Publisher, 2012).

36 There is an abundant literature on the potential conflicts between environmentalism as a doctrine and the respect of human rights, both from a theoretical and an empirical perspective. See e.g. T. Hayward, Political Theory and Ecological Values (London: Polity Press, 1998); R. Neumann, Imposing Wilderness : Struggles over Livelihood and Nature Preservation in Africa (Berkeley : University of California Press, 1998); M. Dowie, Conservation Refugees: The Hundred Years Conflict between Global Conservation and Native Peoples (Cambridge MA : MIT Press, 2009).

37 On differential treatment in international law see: D. B. Magraw, 'Legal Treatment of Developing Countries: Differential, Contextual and Absolute Norms' (1989) 1 Colorado Journal of International Environmental Law and Policy 69 ; Ph. Cullet, Differential Treatment in International Environmental Law (Aldershot : Ashgate, 2003) ; L. Rajamani, Differential Treatment in International Environmental Law (Oxford University Press, 2006). 
One key aspect, well conceptualized in political theory, ${ }^{38}$ is the identification of the object (resource - e.g. financial resources or technology - or burden - e.g. emissions-reductions) that is to be distributed, the actors among (or levels at) which the distribution must take place (the 'only States' picture is becoming increasingly inaccurate), and the criteria for the distribution of each object. ${ }^{39} \mathrm{~A}$ rigid contrast between just two categories of States may not be a problem in some contexts, whereas it may be deeply problematic in others.

The Montreal Protocol on Substances that Deplete the Ozone Layer ${ }^{40}$ introduces a binary differentiation (between article 5(1) States - or developing States - and the rest - developed countries), just as does the Kyoto Protocol (between Annex I - or Annex B - and the rest - developing countries). Yet, the Montreal Protocol uses this differentiation for purposes of assistance and deadlines, but not to avoid imposing clear obligations on one category of actors, as does Kyoto. Under the Montreal Protocol, all States have to eliminate progressively the production and consumption of listed substances. As I just noted, developing States are only given more flexible deadlines and some assistance. This technique, strikes a balance between fairness and effectiveness that, in practice, has proved very effective.

The search for balance must clearly disentangle objects of distribution, distribution actors and levels, and the criteria of distribution. Such an exercise would provide the 'groundwork' for any attempt at calibrating differentiation. Thereafter, calibration would have to be conducted on a regime-by-regime or even object-by-object (as characterised above) basis. It is quite likely that the differentiation most appropriate to the climate change regime (or for certain objects within it, such as emissions-reduction commitments or financial and/or technological assistance) may not be relevant for the regulation of persistent organic pollutants or biodiversity conservation. Thus, persuasive arguments on how to differentiate in a given context would have to be provided.

\subsubsection{Decarbonisation}

Recalibration is also required in connection with energy. The 'decarbonisation' knot faces a daunting challenge, namely the renewed commitment to fossil fuels arising from the considerable amounts of resources invested in the last ten years on the exploration and extraction of fossil energy resources. ${ }^{41}$ The

38 See e.g. M. Gardiner, 'Ethics and Global Climate Change’ (2004) 114 Ethics 555 ; S. Vanderheiden (ed.), Political Theory and Global Climate Change (Cambridge MA : MIT Press, 2008)

39 See J. E. Vinuales, 'Balacing Effectiveness and Fairness in the Redesign of the Climate Change Regime’ (2011) 24 Leiden Journal of International Law 223.

40 Montreal Protocol on Substances that Deplete the Ozone Layer, 16 September 1987, 1522 U.N.T.S. 29.

41 See L. Maugeri, 'Oil: The Next Revolution', Discussion Paper 2012-10, Belfer Center for Science and International Affairs, Harvard Kennedy School, June 2012. 
companies and governments that have consented such large 'sunk costs' have thereby committed to recover the investment in the future. ${ }^{42}$

It is difficult to assess the implications of this phenomenon for the question of 'decarbonisation'. At the very least, it implies (from the more to the less obvious) (i) that achieving any level of decarbonisation will be a confrontational endeavour, (ii) that geo-engineering techniques will play a significant role in future decarbonisation efforts, ${ }^{43}$ and (iii) that the possibility of reaching the 'critical mass' referred to in the discussion of participation may be compromised in some industrial sectors (energy production) or even regulatory areas (climate change more generally).

This is a particularly important front and should be treated as a priority in global environmental negotiations. Engaging in a fossil energy path would place a compelling straitjacket on a number of international negotiations ${ }^{44}$ or, at least, on the practical relevance of their outcomes. Yet, so far, the governance of fossil energy resources has followed a particularistic or bilateral path. The few codification efforts (particularly at the UN International Law Commission) have been staunchly resisted by a majority of States. As long as energy governance will continue to follow the 'bilateral model', 45 progress in the multilateral negotiations towards decarbonisation will remain elusive, because the fossil path made possible at the bilateral level will pre-determine the pace and effectiveness of the multilateral decarbonisation negotiations.

42 This commitment to fossil fuels would likely be unsustainable if future generations (as the main 'group' stakeholder) were asked whether they feel 'indifference', 'regret' or 'gratitude' with respect to the decision to engage in the fossil path. See M. W. Anderson, M. Teisl, C. Noblet, 'Giving a voice to the future in sustainability: Retrospective assessment to learn prospective shareholder engagement' (2012) 84 Ecological Economics 1. But the results of such a retrospective assessment would, in all likelihood, depend on (i) the net benefits of the fossil fuel path (as compared to its contribution to climate change and the negative effects of climate change), (ii) the distribution of the costs/benefits among different groups within future generations (the future - as the current - population within a developing country may, in earnest, feel 'grateful' despite the effects of such a path on climate change). It must be noted that this approach is entirely based on consequentialist reasoning (as is the case, more generally, of economic science).

43 This potential implication highlights the importance for global environmental governance of understanding the framework applicable to geo-engineering. On this point see C. Redgwell, 'Geoengineering the Climate: Technical Solutions for Mitigation Failure or Continuing Carbon Addiction?' (2011) 2 Carbon and Climate Law Review 178.

44 On the different fora where energy negotiations are being conducted see the overview in J. Pauwelyn (ed.), Global Challenges at the Intersection of Energy, Trade and the Environment (Geneva: The Graduate Institute, 2010).

45 See J. E. Viñuales, 'Vers un droit international de l'énergie : Essai de cartographie', in D. Bentolila, M. G. Kohen (eds.), Mélanges en l'honneur du professeur Jean-Michel Jacquet (Paris : LexisNexis, forthcoming 2013) [currently available as CIES Research Paper no. 14, September 2012 : http://graduateinstitute.ch/cies/publications/CIES_Research_Papers.html] 


\subsubsection{Innovation and dissemination}

Technological breakthrough may, however, offer powerful weapons against a fossil energy path. Progress in technology involves not only innovation but also dissemination.

As Amartya Sen once noted in connection with famines, it is not necessarily the availability of food but rather the access to it by those in need that must be tackled to prevent famines. ${ }^{46}$ A similar argument could be made for technology. However, unlike food, the very strategies used to steer technological innovation (particularly intellectual property rights or 'IPRs') have implications for the subsequent access to such technology (because of the monopoly given by IPRs, which leads to higher prices and, in some cases, to a refusal to license the technology to potentially competing companies).

This is therefore not only a technological challenge, but also an economic (how to foster innovation) and a legal one (without severely restricting access).${ }^{47}$ Economic and legal innovation, for instance by the creation of 'IPRs markets' where individual licenses to use a given technology are exchanged for a price at a low transactional cost and without restrictions based on industrial competition arguments, ${ }^{48}$ is therefore as necessary as technological innovation.

The above four knots are, as such, broad frontlines within which other area- or issue-specific frontlines would have to be open. But, by focusing on these knots, and on calibration efforts within each of them, we would have a clearer picture of whether (and to what extent) progress is being made in global environmental governance. In turn, clarity on how environmental protection is moving forward would provide credible regulatory threats (or enhanced legal certainty) and thus incentivise the private sector to adjust their investment decisions accordingly. The four knots must therefore be seen as a set of 'priorities' within the overall strategy towards the enhancement of global environmental governance.

\subsection{Relations with the concept of sustainable development}

The next question is what should be the connection between what could be called the 'four knots model' and the use of the concept of sustainable development. The starting point of any answer is that the concept of sustainable development will be with us for many years to come. Its use in international

46 See A. Sen, Poverty and Famines. An Essay on Entitlement and Deprivation (Oxford University Press, 1981).

47 For a recent comparative survey of techniques used by three governments to direct research into energy innovation see L. Diaz Anadon, 'Missions-oriented RD\&D Institutions in Energy Between 2000 and 2010: A Comparative Analysis of China, the United Kingdom, and the United States' (2012) 41 Research Policy 1742.

48 See A. H. B., Monk, 'The Emerging Market for Intellectual Property: Drivers, Restrainers, and Implications’ (2009) 9 Journal of Economic Geography 469. 
practice is pervasive ${ }^{49}$ and it is still the most powerful tool for gathering stakeholders around the same table of negotiation. But to what extent should we use this stake-holder gathering power?

As noted before, the use of this power comes at a price, namely the potential overburdening of a negotiation and the inability of setting clear priorities. This power should therefore be used where gathering consensus is more important than (as it is a preliminary step towards) refining a regime to enhance its implementation. In more specific terms, out of the several functions of 'Conference Diplomacy' identified in the political science literature, ${ }^{50}$ only some of them ('popularizing issues and raising consciousness', 'generating new information and identifying new challenges for governments', 'providing general alerts and early warnings of new threats', 'promoting mass involvement of new actors') may be facilitated by the use of the concept of sustainable development, whereas other more specific ones ('agenda setting', 'galvanizing administrative reform', 'adopting new norms, certifying new doctrinal consensus, and setting global standards') may in fact be disserved by a focus as broad as sustainable development.

This basic observation may be relevant to decide which international forum is more appropriate to push forward advances in global environmental governance. Whereas the era of broad global environmental conferences may not be over, the dose of sustainable development used for different purposes may have to be more carefully set.

\section{An Initial Exploration}

Let me now come back to the initial broad question: what fundamental aspects of global environmental governance must be changed in order to make progress in the implementation of international environmental law? The contention in this article is that we must direct our efforts towards the calibration of the four knots identified above. In its current state, the conceptual chart outlined in this article provides a tool to organise a diverse array of scattered developments in order (i) to assess whether progress is actually being made in global environmental governance; (ii) the extent of such progress (the degrees of calibration); and (iii) what areas are lagging behind and require renewed efforts. Of course, 'progress' is no longer a word that we easily use today. It is ideologically tainted and, in some circles, it is deemed as utopian or even insidious. The only way to assuage concerns in this respect is to define what I mean by 'progress' in global environmental governance: more public participation; more accurate and fact-sensitive differentiation; less reliance on

\footnotetext{
49 See Barral, above n. 5.

50 See P. M. Haas, 'UN Conferences and Constructivist Governance of the Environment' (2002) 8 Global Governance 73.
} 
fossil fuels; more innovation and diffusion of technology. Each knot must be calibrated to some degree, a process that will depend among others on the political and economic feasibility of achieving a certain degree of calibration.

The articles published in this guest-edited issue of RECIEL are intended to guide such a process by providing an initial exploration of ways in which some degree of calibration could be achieved. As noted in the introduction, articles were elicited for each knot. Yet, some of the articles addressed cross-cutting questions and are relevant for the entire model. For this reason, instead of introducing the articles following the order of the four knots model, I have taken the liberty of organising them in a different order that better reflects the overall understanding that this project seeks to advance. My comments below are intended not only to introduce the articles in this issue but also to engage with the ideas expounded by the authors and signal issues or areas where I believe that further research would be welcome.

The article by Elisa Morgera and Annalisa Savaresi, both from the University of Edinburgh, takes a broad view of two concepts, 'green growth' and 'green economy', developed to tackle the ambiguities entailed by the concept of sustainable development. It then discusses the concept that was eventually included in the outcome document of the Rio+20 Summit, which the authors see, in many ways, as a watered-down version of the concepts initially proposed. The article can be read in several ways. What I personally gather from the discussion is that, as one moves from 'green growth', to the initial meaning of 'green economy' (green economy 1), to the 'green economy' as eventually characterized by the Rio+20 outcome document (green economy 2), the meaning of the concept becomes more and more blurred. Underlying this increasing vagueness is the fact that the concept of 'green growth' was essentially a developed country ('OECD') creature, which was progressively watered-down throughout the negotiations with developing countries. This explains the conclusion reached by Morgera and Savaresi, namely that the 'green economy', as characterized in the outcome document, does not add much to the question of how to implement international environmental law. In fact, aside from some policy considerations relating to participation, which are important and welcome, the outcome document neutralized the main interest of introducing concepts such as the 'green economy' by recalling that the template is still the concept of sustainable development. Another element that can be derived from the article by Morgera and Savaresi is that, whether we focus on 'green growth', 'green economy 1' or 'green economy 2', the balance among the three pillars of sustainable development is clearly on the development/growth side. As some early proponents of the green economy suggested, ${ }^{51}$ this is an economic stimulus package with an environmental dimension, not the other way around. Over the years, the focus on

51 See Barbier, supra n. 6. 
development/growth has raised vivid controversies. Alternative frameworks, such as 'de-growth' ${ }^{52}$ or 'planetary boundaries', ${ }^{53}$ have been advanced, but they all have their own problems. ${ }^{54}$ Moreover, policy-makers would find it particularly difficult, in practice, not to follow a development/growth model. An interesting element introduced by the Rio+20 outcome document in this connection is a process towards the development of measures of welfare that take into account a broader set of variables, including the state of the natural environment. ${ }^{55}$ Introducing the state of natural resources and the environment into the picture would be a way to better account for the negative externalities of development/growth in aggregate welfare measures. In some cases, the improvement on the human condition may require additional pressure on the environment whereas in others, particularly in those countries where the levels of human welfare are already high, environmental protection may be given a higher priority.

The latter point raises, in turn, another difficult question, namely differentiation. As already noted, differentiation is not only a matter of equity or fairness, but also one of effectiveness. The fundamental question of financing pro-environment measures is conditioned by the prior development of an appropriate differentiation scheme. Indeed, global environmental governance will not be effective if it is not calibrated to the different needs of States. Differentiation is analyzed in the articles of Joost Pauwelyn, from the Graduate Institute, Geneva, and Dan Farber, from the University of California, at Berkeley. Pauwelyn advocates for more, rather than less, differentiation in the structuring of the rights and obligations contemplated in multilateral environmental agreements (MEAs). He compares the trends towards the creation of different categories of States in the contexts of both trade and climate change agreements and concludes, based on the experience of the world trade system, that more differentiation would not only be more equitable but that it is also a condition for the effectiveness of MEAs. In his contribution, Farber focuses on one key feature of emerging economies, namely their dual 'developed' and 'developing' nature. He argues that the principle of common and differentiated responsibilities (CBDR) should be reinterpreted to capture the responsibilities of wealthy and more polluting areas towards the poorer and

52 The theory of degrowth has deep roots. In recent years, economists have tried to assess what effects degrowth policies would actually have. See e.g. G. Kallis, Ch. Kerschner, J. Martinez-Alier, 'The economics of degrowth' (2012) 84 Ecological Economics 172 (assessing recent research and refining the relevant research questions).

53 V. Galaz, F. Biermann, C. Folke, M. Nilsson, P. Olsson, 'Global environmental governance and planetary boundaries: An introduction’ (2012) 81 Ecological Economics 1.

54 D. Tokic, 'The economic and financial dimensions of degrowth' (2012) 84 Ecological Economics 49 (concluding that degrowth policies would leave to an economic implosion); W. H. Schlesinger, 'Planetary boundaries: thresholds risk prolonged degradation' (2009) Nature Reports Climate Change, doi:10.1038/climate.2009.93. (arguing that management through thresholds encourages policy-makers to pollute up to the threshold instead of taking action before reaching it).

55 See The future we want, supra $\mathrm{n} .24$, para 38. 
more vulnerable areas within emerging countries. He then discusses the implications of this novel understanding of CBDR, particularly for the domestic allocation of funds received by emerging economies from international sources.

The articles by Carlos Correa, from the University of Buenos Aires and the South Center, and Derek Eaton, from the Centre for International Environmental Studies, in Geneva, explore legal and economic innovation to foster technology innovation and diffusion. Correa persuasively argues that there is currently a disconnect between the policy rationale pursued by developed countries in international negotiations (i.e. intellectual property rights (IPRs) are the best strategy to steer technological innovation), and a now well established body of empirical research that shows that the IPRs system may well be preventing innovation in environmentally sound technologies (ESTs). Correa concludes that reforming the IPRs system would provide significant benefits not only for developing countries (by facilitating access to ESTs) but also for developed countries, by reducing the important legal obstacles that are faced by genuine innovators. Eaton argues from a more integrated policy approach to innovation and diffusion of technology that would redirect IPRs, trade disciplines and investment agreements towards same direction, i.e. facilitating the transition to the green economy described in UNEP's 2011 report. Both Correa and Eaton highlight the variety of factors that govern (or distort) the connection between, on the one hand, IPRs or finance, and, on the other hand, innovation and technology transfer. Their perspectives strengthen the need for resource-specific differentiation in order to overcome the commonplace and unhelpful polarization between North and South.

The article by David Cassuto, from Pace Law School, and Romulo Sampaio, from the FGV Law School in Rio, returns to the first knot of the model, i.e. participation. They dispel the view that participation is to be considered as an additional hurdle and highlight instead the advantages of participation to reduce uncertainty and to make decisions taken under conditions of uncertainty more legitimate. In decision-making processes, participation is important to gather and disseminate information on a given issue. The contribution of participatory processes, which may range from highlighting overlooked data to providing a better view of the social implications of a given decision, can reduce the uncertainties faced by decision/policy-makers. Even in those cases where the level of uncertainty remains high, participation encourages ownership of the decisions and policies adopted to tackle an environmental problem. The article by Cassuto and Sampaio thus provides an additional rationale for fostering participatory processes. Another rationale is provided in the article by Carina Costa de Oliveira, from the Brasilia Federal University. She argues that sustainable development partnerships (SDPs) could become a key instrument for bringing broad sustainable development goals, expressed in international policy instruments, down to a level of specificity that permits their implementation. Generally speaking, both articles converge in that they provide 
additional arguments for authorities to see participation as an outsourcing tool, at times increasing the pressure on governments to act (participatory checks) and at times relieving some of the pressure (ownership, information input, and refinement of broad goals).

Taken together, the contributions to this special issue of RECIEL set out to clarify the way forward after Rio +20 by providing, at the same time, an overall analytical framework and a selection of 'acupunctural points' that, it is submitted, must be tackled as a priority matter. The programme outlined here would greatly benefit from further discussion and debate, particularly at the level of (i) the definition of progress in global environmental governance, (ii) clarification of degrees (for each knot), combinations (of calibrated knots) and potential techniques to effect such calibration, and, of course, (iii) empirical assessment. RECIEL offers the ideal setting to launch and hopefully pursue this debate. 